\title{
Supplementation with DHA and the psychological functioning of young adults
}

\author{
D. Benton ${ }^{1 *}$, R. T. Donohoe ${ }^{1}$, D. E. Clayton ${ }^{1,2}$ and S. J. Long ${ }^{1}$ \\ ${ }^{1}$ Department of Psychology, University of Wales Swansea, Swansea SA2 8PP, UK \\ ${ }^{2}$ Glion Institute of Higher Education, Les Roches-Gruyère University of Applied Sciences, Rue de l'Ondine 20, \\ CH-1630 Bulle, Switzerland \\ (Submitted 5 October 2011 - Final revision received 27 January 2012 - Accepted 27 January 2012 - First published online 13 April 2012)
}

\section{Abstract}

The grey matter of the brain contains high levels of the essential nutrient DHA. Although the role of DHA in the developing brain and in dementia has attracted attention, its influence on the brain of the healthy adult has been little considered. A total of 285 young adult females took $400 \mathrm{mg}$ of DHA, in a double-blind, placebo-controlled trial, for $50 \mathrm{~d}$. After $50 \mathrm{~d}$, recently acquired information was more likely to be forgotten by those who had consumed DHA. No significant differences in mood, reaction times, vigilance or visual acuity were found.

\section{Key words: DHA: Memory: Mood: Vigilance}

About $50-60 \%$ of the dry weight of the brain is lipid, of which $35 \%$ consists of PUFA ${ }^{(1)}$. In fact, the nature of the dietary intake of PUFA has neurophysiological consequences, as the nature of the diet influences the composition of cell membranes and thus the functioning of the brain ${ }^{(2)}$. A review suggested that the consumption of $n-3$ PUFA might beneficially affect neuronal composition, neurotransmission and cognitive functioning. Neurotransmission is influenced by two mechanisms: by changing membrane fluidity and by increasing the release of neurotransmitters ${ }^{(3)}$. Epidemiological and developmental research has suggested the role of $n-3$ PUFA in the regulation of monoamine-mediated systems, cognition and affect: for example, $n$-3 PUFA have been implicated in depressive disorders, suicide, aggression and impulsivity ${ }^{(4,5)}$.

Although low levels of DHA have been associated with neurodegenerative diseases including dementia ${ }^{(6-8)}$, the literature is limited and inconsistent. A prospective study ${ }^{(9)}$ measured the plasma fatty acid levels in older adults, but over a 3-year period they were not associated with changes in cognition. A cross-sectional longitudinal study ${ }^{(10)}$ examined the relationship between fish $/ n-3$ consumption and cognitive performance and after a 6-year follow-up found no association. However, a 13-year prospective study of 3294 adults found that selfreported cognitive difficulties were less frequent in those with a higher consumption of $n-3$ PUFA, even after adjustment for depressive symptoms. The authors concluded that cognitive complaints were less frequent among the elderly who had a high intake of $n-3$ PUFA 13 years earlier ${ }^{(11)}$. Although some observational studies have found that a better $n-3$ PUFA status was beneficial, it is important that a 2 -year double-blind, randomised, controlled trial did not ${ }^{(12)}$. Healthy older adults (aged 70-79 years) took, each day, $200 \mathrm{mg}$ EPA plus $500 \mathrm{mg}$ DHA, or olive oil, but there was no significant difference in cognitive performance. The authors concluded that the relatively short length of the intervention period might have masked the potential beneficial effect of fish oil.

When considering the rate of cognitive decline, the timescale of supplementation may be critical. Benton ${ }^{(13)}$ noted that age-related changes in brain structure begin to occur up to 60 years before they become overtly apparent as cognitive problems. The time-scale of studies of older adults may have in many instances failed to reflect the slow speed of the processes they were trying to reduce. Yet it is known that there is a rapid turnover of fatty acids in the brain, such that over a relatively short period the structure of cell membranes will reflect the diet of the recent past. In rats, Rapoport ${ }^{(14,15)}$ used radio-labelled PUFA to establish the rate at which they were incorporated into brain phospholipids and found that $3-5 \%$ of arachidonic acid (AA) and 2-8\% of DHA are lost each day by metabolic mechanisms, to be potentially replaced by dietary sources. Such a rate of turnover gave half-lives of 1-2 weeks for the exchange of AA and DHA between the

Abbreviation: AA, arachidonic acid.

*Corresponding author: D. Benton, email d.benton@swansea.ac.uk 
plasma and brain. In human subjects, it was determined by positron emission tomography that the human brain consumes $17.8 \mathrm{mg} / \mathrm{d}$ of $\mathrm{AA}$ and $4.6 \mathrm{mg} / \mathrm{d}$ of DHA; values that did not change significantly with age ${ }^{(16)}$. Thus, dietary supplementation may increase the levels of plasma PUFA and in this way influence the nature of their turnover in the brain and the resulting PUFA profile. It should, however, be remembered that there are bodily compensations for a diet low in PUFA, so that there is up-regulation of liver enzymes associated with the metabolism of AA and DHA from their precursors ${ }^{(17)}$.

Although there is a report in young adults that supplementation with DHA for 12 weeks was associated with increased cerebral blood flow ${ }^{(17)}$, cognition was not influenced and in fact there has been little study on the influence of PUFA supplements in this age group. Fontani et $a l .{ }^{(18,19)}$ reported that $n$-3 supplements increased aspects of mood although never was a significant difference with the placebo reported. Antypa et $a l .{ }^{(20)}$ gave $n$-3 PUFA supplements for a month and measured performance on a battery of tests and found few effects, although the $n$ - 3 PUFA group made fewer risk-averse decisions.

In summary, a dietary increase of $n-3$ PUFA may influence behaviour by changing the structure of cell membranes and enhancing neurotransmission ${ }^{(2)}$. To date, much of the research has considered cognitive decline; however, as it takes place over many years, it would not be expected to be susceptible to a relatively short-term intervention. A possibility that has been little considered is that there might be in young adults a beneficial response to a relatively short-term intervention; one that is long enough to reflect the rate of PUFA turnover. That is, rather than looking to prevent cognitive decline, functioning may be facilitated in the short-term by providing an optimal intake for the healthy brain. The present study therefore gave fatty acid supplements to young, healthy adults and monitored cognition and mood.

\section{Methods}

For practical reasons, dictated by the ability to test a given number of subjects, the study took place in two phases. Initially, a group of 150 was recruited and subsequently a second group of 150 subjects took part 3 months later. The data presented are for these two parts combined. As it was possible that changes in diet associated with the time of year might have influenced the findings, initially the statistics allowed for any differences between the two halves of the study to be distinguished. As differences did not occur, they are not further mentioned. All subjects took the battery of cognitive tests and then were randomly allocated to either the DHA or placebo condition using a double-blind procedure. Following baseline testing, four capsules were taken each day. The cognitive battery was taken for a second time after $25 \mathrm{~d}$ and for a third time after $50 \mathrm{~d}$. The tests were taken in the following order: mood, word list immediate recall, reaction times, vigilance, word list delayed recall. In addition, with the first half of the subjects, visual acuity was measured after vigilance. With the second half of the subjects, visual acuity was not measured but the recall of capital cities was the first test of the battery, but only during the third testing session (after $50 \mathrm{~d}$ ). Trying to recall missing capitals on this occasion was the final test of the sequence. The study was conducted according to the guidelines of the Declaration of Helsinki and all procedures were approved by the ethics committee of the Psychology Department of Swansea University. All subjects gave written informed consent.

\section{Subjects}

A total of 305 adult females, mean age $21 \cdot 8$ years and all university students were recruited when they responded to a poster. They gave written informed consent and were paid $₫ 30$ for taking part. The procedure was approved by the local ethics committee. No subject was taking fish oil, or similar fatty acid supplement, and all reported that they were in good health. In total, 285 finished the trial although none reported withdrawing because of side effects.

\section{Supplements}

Placebos and active capsules were produced by Martek Biosciences Corporation. The active DHASCO ${ }^{\circledR}$ capsules contained deodorised and bleached oil derived from the microalgae Crypthecodinium cohnii, which was added to high-oleic sunflower oil so that $40 \%$ of the resulting mixture was DHA. Antioxidants, tocopherols $(0.025 \%)$ and ascorbyl palmitate $(0.025 \%)$, and the flavouring ethyl vanillin with a sweet, creamy, vanilla taste and odour, were added. The fatty acid profile was as follows 10:0 (0.5\%); $12: 0(3.8 \%) ; 14: 0(12 \cdot 1 \%)$; $16: 0(7 \cdot 8 \%) ; 18: 0(1.0 \%) ; 18: 1(31.2 \%) ; 18: 2(1.5 \%) ; 22: 0$ $(0 \cdot 3 \%) ; 22: 6$ (DHA) $40 \cdot 1 \%$. Thus, there was no detectable EPA or other long-chain PUFA. With this as composition, four $250 \mathrm{mg}$ capsules a day offered $400 \mathrm{mg}$ of DHA. The placebos were identical in size, colour and smell to the active capsules and contained maize/soya oil to which ethyl vanillin was added. The fatty acid profile was as follows: 16:0 (11.0\%); $18: 0(3.0 \%) ; 18: 1$ (23.3\%); $18: 2$ (56.7\%); $18: 5$ (4.1\%); $20: 0$ $(0 \cdot 4 \%) ; 20: 1(0 \cdot 3 \%) ; 22: 0(0 \cdot 2 \%)$.

\section{Cognitive tests}

\section{Recall of word list}

For this test, three matched lists of thirty nouns were created, all of five letters and one syllable in length. Nouns were selected on the basis of high frequency (AA: > 100/million words; A: 50-100/million words), high imagery and high concreteness ${ }^{(21)}$. They were presented at the rate of one word/s. Immediately after presentation, the subjects wrote down as many words as they could recall in 2 min (immediate memory task). Approximately $25 \mathrm{~min}$ later, following the other tests, the subjects again tried to recall the words (delayed memory task). The same word list was presented to all subjects at a particular testing session.

\section{Recall of capitals}

This test was only given to the second group of subjects. As the test could not be meaningfully repeated, it was administered 
only during the final testing session, that is after taking the capsules for $50 \mathrm{~d}$. In a pilot study, the subjects were asked to report the capitals of various countries and, if they were unable to recall them at that moment, to rate whether they thought they knew them. From these responses, a list of thirty countries was created, which consisted of countries where it was common to report that they had a feeling that they knew the capital although they were unable to recall the same.

The list of thirty countries was given to the subjects who, where possible, mentioned the capital. Where they did not know the answer, they rated their 'feeling of knowing' on a six-point scale $(1=$ very strong feeling of knowing to $6=$ definitely do not know).

Having carried out the rest of the test battery, the list of countries was given a second time and any capitals subsequently remembered were reported. The responses obtained on the second occasion were expressed as a portion of the number of answers previously unanswered.

\section{Reaction times}

The reaction time procedure was based on that of Jensen ${ }^{(22)}$. On a panel, eight lamps were arranged in a semicircle 5.5 inches from a central button (the home key). The index finger was placed on the home key. Following a warning tone, one of the eight lamps flashed and the subject pressed the button in front of the illuminated lamp. The decision time is the time taken to lift the finger from the home key. Simple and choice decision times for each of two, four and eight lamps were measured over twenty trials.

\section{Rapid information processing task}

A computer generated a series of digits at the rate of 100 digits/ min for $5 \mathrm{~min}$. Subjects pressed the space bar when they detected target sequences of three consecutive odd or three consecutive even digits. In this manner, eight of these sequences were presented every minute. The numbers of correct and incorrect responses were analysed.

\section{Visual acuity}

Visual acuity was measured using Snellen charts and was only given to the first group of subjects. To increase sensitivity, the charts were read from a distance of $5 \mathrm{~m}$ rather than the recommended $3 \mathrm{~m}$. Thus two charts were presented, one of numbers and one of letters. Both charts were presented to the right, and then both were presented to the left, eye. The measure analysed was the total number of letters and numbers that were not reported correctly.

\section{Mood assessment}

Visual analogue scales ( $100 \mathrm{~mm}$ lines) were used to assess how the subjects had felt 'during the past week': were they energetic-tired, clearheaded-confused, composed-anxious, confident-unsure, elated-depressed and agreeable-hostile? These dimensions were derived from the factor analysis that was carried out when the Profile of Mood States questionnaire ${ }^{(23)}$ was developed.

\section{Side effects}

After taking the capsules, the subjects were asked if they had experienced any side effects and also to indicate whether they believed they were taking the active capsules, placebo or could not tell.

\section{Statistical analysis}

Most analyses of the influence of DHA used a three-way ANOVA; DHA/placebo $\times$ first/second group of subjects $\times$ time (tested for the first, second or third time), with the last as a repeated-measures factor. Significant interactions were explored by the calculation of simple main effects. Whether the results came from the first or second half of the subjects did not influence the findings and these details are therefore not reported. The effects of the capsules on the recall of capitals, and 'feeling of knowing', were examined using $t$ tests.

\section{Results}

\section{Word list recall}

When recall of the word lists was considered, the interaction capsule $\times$ time $\times$ immediate/delayed recall $(F(2,566)=4 \cdot 41$, $P<0 \cdot 01)$ reached significance. Fig. 1 illustrates the interaction that reflects differences between immediate and delayed recall; that is the amount forgotten. Those taking DHA tended to forget more at the end of the study. Post hoc tests found that those taking DHA rather than the placebo forget more after $50 \mathrm{~d}(P<0 \cdot 01)$.

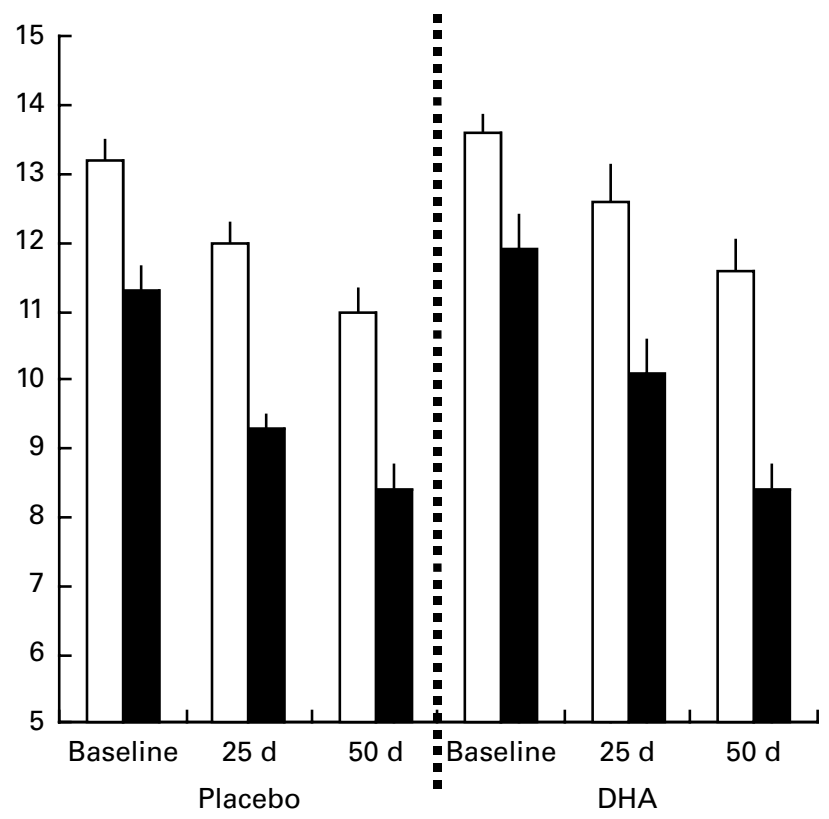

Fig. 1. The influence of DHA supplementation on forgetting. The data are the mean number of words forgotten between immediate $(\square)$ and delayed ( $\boldsymbol{\square})$ recall of the word list. Those taking DHA forget more after $50 \mathrm{~d}(P<0.01)$. 
To consider whether this was a genuine effect, rather than simply due to statistical chance, the sample was reanalysed in two halves reflecting the first half of the subjects that had been run as one group and the second half that was tested some months later. In both cases, there was a trend for forgetting to be worse at the end of the study in those who took DHA, albeit it did not reach statistical significance. The number forgotten at the end of the study for the first group of subjects was placebo 2.6 (SE 0.21) and DHA $3 \cdot 2$ (SE 0.28), $P<0.07$, figures that compared well with the second half of the study that produced values for the placebo of $2 \cdot 6$ (SE 0.27) and DHA $3 \cdot 2$ (sE 0.29), $P<0 \cdot 09$. There was evidence of a consistent pattern that when these data were merged, it produced an overall effect of $2 \cdot 6$ (SE 0.19) words being forgotten with the placebo and $3 \cdot 2$ (SE 0.19) with DHA $(P<0 \cdot 01)$.

\section{Recall of capitals}

Table 1 reports that those taking the DHA did not differ significantly in terms of the number of capitals initially recalled, the feeling that they knew the correct answer but were unable to recall it, or the number of additional capitals recalled when the task was undertaken for a second time.

\section{Mood}

The interaction capsule $\times$ time failed to reach statistical significance in the case of agreeable $(F(2,566)=0 \cdot 47$, NS), clearheaded $(F(2,566)=0 \cdot 02$, NS), composed $(F(2,566)=0 \cdot 38$, NS), confident $(F(2,566)=0 \cdot 62$, NS $)$, elated $(F(2,566)=0 \cdot 19$, NS) and energetic $(F(2,566)=1 \cdot 57$, NS). Mean values are presented in Table 1.

Table 1. The influence of DHA supplementation on mood and various measures of cognitive functioning* (Mean values with their standard errors)

\begin{tabular}{|c|c|c|c|c|c|c|}
\hline & \multicolumn{2}{|c|}{ Baseline } & \multicolumn{2}{|c|}{$25 d$} & \multicolumn{2}{|c|}{$50 d$} \\
\hline & Mean & SE & Mean & SE & Mean & SE \\
\hline \multicolumn{7}{|c|}{ Recall of capital cities } \\
\hline \multicolumn{7}{|l|}{ Initial recall } \\
\hline Placebo & & & & & 14.0 & $5 \cdot 8$ \\
\hline DHA & & & & & $12 \cdot 5$ & $5 \cdot 2$ \\
\hline \multicolumn{7}{|c|}{ Feeling of knowing } \\
\hline Placebo & & & & & $5 \cdot 0$ & 0.56 \\
\hline $\mathrm{DHA}$ & & & & & $5 \cdot 0$ & 0.52 \\
\hline \multicolumn{7}{|c|}{ Second recall } \\
\hline Placebo & & & & & 1.4 & 0.15 \\
\hline DHA & & & & & 1.4 & 0.15 \\
\hline \multicolumn{7}{|c|}{ Decision times } \\
\hline Placebo & 353.7 & 4.4 & 353.2 & 3.5 & 353.2 & 3.4 \\
\hline DHA & 346.9 & 4.4 & 342.4 & 3.6 & $346 \cdot 1$ & $3 \cdot 4$ \\
\hline \multicolumn{7}{|l|}{ Vigilance } \\
\hline \multicolumn{7}{|l|}{ Correct } \\
\hline Placebo & 4.2 & 0.11 & 4.6 & 0.12 & 4.7 & 0.12 \\
\hline $\mathrm{DHA}$ & 4.3 & 0.12 & 4.7 & 0.12 & 4.9 & 0.13 \\
\hline \multicolumn{7}{|l|}{ Incorrect } \\
\hline Placebo & $2 \cdot 6$ & 0.86 & $2 \cdot 1$ & 0.24 & $2 \cdot 1$ & 0.36 \\
\hline $\mathrm{DHA}$ & 4.0 & 0.89 & $2 \cdot 7$ & 0.25 & $2 \cdot 4$ & 0.37 \\
\hline \multicolumn{7}{|l|}{ Visual acuity } \\
\hline Placebo & 20.5 & 1.8 & 19.4 & 1.8 & $18 \cdot 9$ & 1.9 \\
\hline DHA & $20 \cdot 2$ & 1.8 & $19 \cdot 2$ & 1.8 & $19 \cdot 1$ & 1.9 \\
\hline \multicolumn{7}{|l|}{ Mood } \\
\hline \multicolumn{7}{|c|}{ Composed-anxious } \\
\hline Placebo & $21 \cdot 2$ & 0.8 & $22 \cdot 7$ & 0.8 & $24 \cdot 3$ & 0.8 \\
\hline $\mathrm{DHA}$ & $20 \cdot 7$ & 0.8 & $21 \cdot 7$ & 0.8 & 23.0 & 0.8 \\
\hline \multicolumn{7}{|c|}{ Agreeable-hostile } \\
\hline Placebo & $26 \cdot 2$ & 0.7 & $26 \cdot 0$ & 0.8 & $27 \cdot 1$ & 0.7 \\
\hline DHA & $25 \cdot 5$ & 0.7 & $25 \cdot 7$ & 0.8 & $26 \cdot 3$ & 0.7 \\
\hline \multicolumn{7}{|c|}{ Elated-depressed } \\
\hline Placebo & $22 \cdot 7$ & 0.9 & $23 \cdot 1$ & 0.9 & $24 \cdot 3$ & 0.8 \\
\hline DHA & 21.5 & 0.9 & $22 \cdot 3$ & 0.9 & $24 \cdot 1$ & 0.8 \\
\hline \multicolumn{7}{|c|}{ Confident-unsure } \\
\hline Placebo & $20 \cdot 4$ & 0.8 & 21.4 & 0.8 & $22 \cdot 7$ & 0.8 \\
\hline $\mathrm{DHA}$ & 19.5 & 0.8 & $20 \cdot 1$ & 0.8 & 21.9 & 0.8 \\
\hline \multicolumn{7}{|c|}{ Energetic-tired } \\
\hline Placebo & $19 \cdot 0$ & 0.9 & $18 \cdot 6$ & 0.9 & $21 \cdot 4$ & 0.9 \\
\hline $\mathrm{DHA}$ & $18 \cdot 0$ & 0.9 & $19 \cdot 6$ & 0.9 & $19 \cdot 7$ & 0.9 \\
\hline \multicolumn{7}{|c|}{ Clearheaded-confused } \\
\hline Placebo & $22 \cdot 1$ & 0.8 & $22 \cdot 6$ & 0.8 & 24.4 & 0.8 \\
\hline DHA & $21 \cdot 2$ & 0.8 & $22 \cdot 4$ & 0.8 & 23.5 & 0.8 \\
\hline
\end{tabular}

* In no instance was there a significant difference between those taking the placebo and DHA. 


\section{Visual acuity}

The capsules did not influence visual acuity (capsule $\times$ time $F(2,286)=0 \cdot 11, \mathrm{NS})$.

\section{Reaction times}

When the median decision times were examined, both the capsule $\times$ number of lamps $\times$ time $(F(6,1692)=0 \cdot 45$, NS) and capsule $\times$ day $(F(2,564)=0 \cdot 47$, NS $)$ interactions were non-significant (Table 1).

\section{Vigilance}

Some subjects with this task used the strategy of continuously pressing the bar so that by chance correct responses registered. Therefore, any subject who had more than twenty errors in a minute was removed from the analysis so that data are presented for 133 taking the placebo and 126 taking DHA. When the number of sequences correctly identified was examined, the capsule $\times$ minutes of the session $\times$ time interaction failed to reach statistical significance $(F(8,2056)=0 \cdot 17$, NS) and similarly the capsule $\times$ time interaction was non-significant $(F(2,514)=0 \cdot 47, \mathrm{NS})$.

When the number of incorrect responses was examined, neither the capsule $\times$ minutes of the session $\times$ time interaction $(F(8,2056)=0.90$, NS) nor the capsule $\times$ time interaction $(F(2,514)=0 \cdot 52$, NS) reached statistical significance.

\section{Side effects}

When asked after $50 \mathrm{~d}$ whether they had experienced any side effects, $92 \%$ of those taking the placebo and $95 \%$ of those taking the DHA, said no. Analysis using $\chi^{2}$ indicated that the responses did not differ depending on which type of capsule had been consumed. In the minority who reported side effects, there was no systematic pattern. Physical and psychological symptoms were equally likely to be reported and when reported they were as likely to be positive as negative. Virtually no symptom was mentioned more than once, but typical examples included increased or decreased pre-menstrual symptoms, feeling less hungry, having more spots or poor fingernails, having improved memory and needing less sleep. When asked to guess which treatment they had received, $60 \%$ of those taking the placebo said that they did not know, $8 \%$ said DHA and $32 \%$ said placebo. Of those taking DHA, 65\% said that they did not know, 19\% said DHA and 16\% said placebo: responses that were not statistically different.

\section{Discussion}

The present study produced little evidence that DHA supplementation influenced either cognition or mood. In fact, the only significant finding was that DHA increased forgetting, an unexpected finding (Fig. 1). That there was a trend for more to be forgotten in both halves of the study supported the view that it was a genuine rather than a chance result, but naturally such a finding requires replication. The failure to find any difference in the ability to recall the names of capitals (Table 1) suggested that there was no problem in retrieving information from long-term memory stores; and so the finding must reflect some other aspect of the memory process. There is, however, in principle, no reason why $n-3$ fatty acid supplementation may not have both positive and negative influences.

The failure to find that mood was influenced is perhaps more surprising (Table 1). Although methodological problems with the studies have been noted, Fontani et al. ${ }^{(18,19)}$ reported that PUFA supplementation improved mood. Benton ${ }^{(24)}$ considered studies that had assessed aggression and in well-controlled trials had given DHA supplements. In this connection, eight studies were subjected to a meta-analysis that established a significant beneficial effect of consuming DHA. As an example, Hamazaki et $a{ }^{(25)}$ reported that $1.5-1.8 \mathrm{~g}$ of $\mathrm{DHA} / \mathrm{d}$ for 3 months decreased aggression towards others, in times of mental stress. There is a parallel between these findings and those of Iribarren et $a l^{(26)}$. In a study of risk factors associated with heart disease in 3581 young adults, the consumption of any fish rich in $n$-3 fatty acids, rather than no fish consumption, was associated with a lower risk of hostility. In fact, there have been suggestions that a tendency to consume a diet low in fat predisposes to being aggressive. When monkeys ate a low-fat diet (30\% rather than $43 \%$ of energy from fat), they displayed more aggression $^{(27)}$.

However, when for a month young adults ate a diet with either 41 or $25 \%$ of energy as fat, ratings of anger-hostility were greater when less fat was consumed ${ }^{(28)}$. However, for 3 months, Rogers et al. ${ }^{(29)}$ gave EPA/DHA supplements to individuals who were mildly to moderately depressed and found no effect on measures of depression or on a range of cognitive tests. They included their findings in a meta-analysis and found that $n-3$ PUFA supplements offered negligible benefits in terms of depressed mood. Interestingly, the effect of the DHA supplement approached statistical significance with a measure of impulsivity ${ }^{(29)}(P<0 \cdot 07)$, suggesting that although mood in general may not be influenced, the possibility that impulsivity and aggression are influenced should be further considered. Antypa et al. ${ }^{(20)}$, however, did not find an influence on impulsivity although $n-3$ PUFA supplementation increased risky decisions.

One possible explanation for the present study's failure to find an influence on mood is that the dose of DHA may be critical. The doses used in the eight studies reviewed by Benton ${ }^{(24)}$ varied but tended to offer at least $1.5 \mathrm{~g}$ DHA and in addition at least $100 \mathrm{mg}$ EPA, usually more. It is an obvious suggestion that the dose in the present study was too low or that in addition EPA should have been provided. An $85 \mathrm{~g}$ portion of salmon offers about $1.2 \mathrm{~g}$ of $n-3$ fatty acids, which puts the dose in perspective, although the recommendation to eat fish twice a week is unlikely to provide the recommended intake of $1000-2000 \mathrm{mg} / \mathrm{d}$.

Nevertheless, the failure to find a general effect on mood agrees with work published since the present study was completed. Jackson et al. ${ }^{(30)}$ gave one of three types of capsules (450 mg DHA + 90 mg EPA; 200 mg DHA + 300 mg EPA; placebo) in healthy young adults aged $18-35$ years. A battery of cognitive tasks and measures of mood were completed before 
and after 12 weeks of supplementation. The authors described the effects of both active treatments as minimal. The only significant finding was that the high-EPA capsules reduced mental fatigue when under high cognitive demand. They concluded that they had not produced solid evidence of any psychological influence. Thus, it does not seem that the giving of EPA was critical.

Jackson et al ${ }^{(30)}$ speculated that their negative findings might have reflected the existing diet not providing a sufficiently low level of $n-3$ fatty acids to allow a benefit from supplementation to be observed. An animal study suggested that there might be a threshold of $n$-3 PUFA intake below which there is a positive response to supplementation. Jensen et al. ${ }^{(31)}$ fed rats diets that differed in their PUFA content. Only when brain levels of $n-3$ PUFA fell to $22 \%$ was the ability to perform in a water maze compromised. Similarly, a South African study found a response to fish oil in under-nourished but not well-nourished children $^{(32)}$.

Jackson et $a l{ }^{(30)}$ considered their finding that ratings of mental fatigue were reduced in those consuming $n$ - 3 PUFA, results similar to those of Antypa et al. ${ }^{(20)}$ who also found less fatigue in individuals taking fatty acids. They speculated that the intake of EPA could modulate the metabolism of proinflammatory AA-derived eicosanoids ${ }^{(33)}$ and that a high level of pro-inflammatory cytokines is associated with tiredness. If so, a reduced AA:EPA ratio might be beneficial in times of cognitive demand. The present findings that DHA supplementation did not decrease fatigue is consistent with this analysis as the present supplement did not contain EPA, although until the administration of DHA and EPA gets to be compared, this remains only an interesting hypothesis.

The present findings, taken together with other recent negative reports, suggest that dietary supplementation with $n-3$ PUFA in healthy, impairment-free populations is unlikely to result in cognitive enhancement. It should, however, be noted that the lack of a measure of baseline fatty acid status or subsequent changes is a weakness of the design that make the generality of the findings uncertain. However, the negative findings are consistent with the few similar studies that have to date been reported in adults ${ }^{(20,29,30)}$ and children ${ }^{(34-37)}$, although in children there is an isolated partially positive report ${ }^{(32)}$. It is therefore surprising that there is a widespread belief that the consumption of $n-3$ fatty acids enhances the functioning of the brain. A website selling $n-3$ supplements claimed thus: 'Recent studies have shown that $n$-3 DHA and EPA can improve learning, problem-solving skills, focus, memory and overall brain function' and recommended the consumption of their product for those from 2 to 102 years of age. A list of the ten best foods and supplements for brain health stated that: 'A lack of $n$ - 3 has been shown to diminish intellectual performance'. It is important that individuals are not given false hopes, as although to date there have been few studies on this topic, the findings are consistently negative.

\section{Acknowledgements}

The funding supplied by Novartis Nutrition Research A.G., and the supply of the DHA capsules and placebos by Martek
Biosciences Corporation, are gratefully acknowledged. No author has any financial interest in matters related to the present study or any other conflict of interest. D. B. and D. E. C. designed the study; R. T. D. collected the data; R. T. D., D. B. and S. J. L. analysed the data and wrote the manuscript.

\section{References}

1. Lauritzen L, Hansen HS, Jorgensen MH, et al. (2001) The essentiality of long chain $n-3$ fatty acids in relation to development and function of the brain and retina. Prog Lipid Res 40, 1-94.

2. Mazza M, Pomponi M, Janiri L, et al. (2007) Omega-3 fatty acids and antioxidants in neurological and psychiatric diseases: an overview. Prog Neurol Psychopharmacol Biol Psychiatry 31, 12-26.

3. Henrich SC (2010) Dietary omega-3 fatty acid supplementation for optimizing neuronal structure and function. $\mathrm{Mol}$ Nutr Food Res 54, 447-456.

4. Hibbeln JR, Umhau JC, George DT, et al. (1997) Do plasma polyunsaturates predict hostility and depression? World Rev Nutr Diet 82, 175-186.

5. Long SJ (2011) Fatty acids depression and suicide. In Lifetime Nutritional Influences on Cognition Behaviour and Psychiatric Illness, pp. 484-524 [D Benton, editor]. Oxford: Woodhead Publishing.

6. Morris MC, Evans DA, Bienias JL, et al. (2003) Consumption of fish and $n-3$ fatty acids and risk of incident Alzheimer disease. Arch Neurol 60, 940-946.

7. Barberger-Gateau P, Letenneur L, Deschamps V, et al. (2002) Fish, meat, and risk of dementia: cohort study. Br MedJ 325 , 932-933.

8. Plourde M (2011) Fatty acid intake and cognitive decline. In Lifetime Nutritional Influences on Cognition Behaviour and Psychiatric Illness, pp. 525-542 [D Benton, editor]. Oxford: Woodhead Publishing.

9. Dullemeijer C, Durga J, Brouwer IA, et al. (2007) n-3 Fatty acid proportions in plasma and cognitive performance in older adults. Am J Clin Nutr 86, 1479-1485.

10. Van de Rest O, Geleijnse JM, Kok FJ, et al. (2008) Effects of fish-oil supplementation on mental well-being in older subjects: a randomized, double-blind, placebo-controlled trial. Am J Clin Nutr 88, 706-713.

11. Kesse-Guyot E, Peneau S, Ferry M, et al. (2011) Thirteen year prospective study between fish consumption, long-chain $n$-3 fatty acids intakes and cognitive function. $J$ Nutr Health Aging 15, 115-120.

12. Dangour AD, Allen E, Elbourne D, et al. (2010) Effect of 2-y $n-3$ long-chain polyunsaturated fatty acid supplementation on cognitive function in older people: a randomized, double-blind, controlled trial. Am J Clin Nutr 91, 1725-1732.

13. Benton D (2010) Neuro-development and neurodegeneration - are there critical stages for nutritional intervention? Nut Rev 68, Suppl. 1, S6-S10.

14. Rapoport SI (2003) In vivo approaches to quantifying and imaging brain arachidonic and docosahexaenoic acid metabolism. J Pediatr 143, Suppl. 4, S26-S34.

15. Rapoport SI (2008) Arachidonic acid and the brain. $J$ Nutr 138, 2515-2520.

16. Rao JS, Ertley RN, DeMar JC Jr, et al. (2007) Dietary $n$-3 PUFA deprivation alters expression of enzymes of the arachidonic and docosahexaenoic acid cascades in rat frontal cortex. Mol Psychiatry 12, 151-157.

17. Jackson PA, Reay JL, Scholey AB, et al. (2012) Docosahexaenoic acid-rich fish oil modulates the cerebral hemodynamic 
response to cognitive tasks in healthy young adults. Biol Psychol 89, 183-190.

18. Fontani G, Corradeschi F, Felici A, et al. (2005) Cognitive and physiological effects of omega-3 polyunsaturated fatty acid supplementation in healthy subjects. Eur J Clin Invest 35, 691-699.

19. Fontani G, Corradesch A, Felici F, et al. (2005) Blood profiles, body fat and mood state in healthy subjects on different diets supplemented with omega- 3 polyunsaturated fatty acids. Eur J Clin Invest 35, 499-507.

20. Antypa N, Van der Does AJ, Smelt AH, et al. (2009) Omega-3 fatty acids (fish-oil) and depression-related cognition in healthy volunteers. J Psychopharmacol 23, 831-840.

21. Paivio A, Yuille JC \& Madigan SA (1968) Concreteness imagery and meaningfulness values for 925 nouns. J Exp Psychol 76, $1-25$.

22. Jensen AR (1987) Individual differences in the Hick paradigm. In Speed of Information-processing and Intelligence, pp. 101-175 [PA Vernon, editor]. Norwood, NJ: Ablex Publishing Corporation.

23. McNair DM, Lorr M \& Droppleman LF (1981) Profile of Mood States. San Diego, CA: Educational and Industrial Testing Service.

24. Benton D (2007) The impact of diet on anti-social, violent and criminal behaviour. Neurosci Biobehav Rev 31, 752-774.

25. Hamazaki T, Sawazaki S, Itomura M, et al. (1996) The effect of docosahexaenoic acid on aggression in young adults. A placebo-controlled double-blind study. J Clin Invest $\mathbf{9 7}$, $1129-1133$.

26. Iribarren C, Markovitz JH, Jacobs DR Jr, et al. (2004) Dietary intake of $n-3, n-6$ fatty acids and fish: relationship with hostility in young adults-the CARDIA study. Eur J Clin Nutr 58, 24-31.

27. Kaplan JR, Manuck SB \& Shively C (1991) The effects of fat and cholesterol on social behavior in monkeys. Psychosom Med 53, 634-642.

28. Wells AS, Read NW, Laugharne J, et al. (1998) Alterations in mood after changing to a low-fat diet. Br J Nutr 79, 23-30.
29. Rogers PJ, Appleton KM, Kessler D, et al. (2008) No effect of $n-3$ long-chain polyunsaturated fatty acid (EPA and DHA) supplementation on depressed mood and cognitive function: a randomised controlled trial. Br J Nutr 99, 421-431.

30. Jackson PA, Deary ME, Reay JL, et al. (2011) No effect of 12 weeks' supplementation with $1 \mathrm{~g}$ DHA-rich or EPA-rich fish oil on cognitive function or mood in healthy young adults aged 18-35 years. BrJ Nutr 107, 1232-1243.

31. Jensen MM, Skarsfeldt T \& Høy CE (1996) Correlation between level of $(n-3)$ polyunsaturated fatty acids in brain phospholipids and learning ability in rats. A multiple generation study. Biochim Biophys Acta 1300, 203-209.

32. Dalton A, Wolmarans P, Witthuhn RC, et al. (2009) A randomised control trial in schoolchildren showed improvement in cognitive function after consuming a bread spread, containing fish flour from a marine source. Prostaglandins Leukot Essent Fatty Acids 80, 143-149.

33. Ferrucci L, Cherubini A, Bandinelli S, et al. (2006) Relationship of plasma polyunsaturated fatty acids to circulating inflammatory markers. J Clin Endocrinol Metab 91, 439-441.

34. Kirby A, Woodward A, Jackson S, et al. (2010) A double-blind, placebo-controlled study investigating the effects of omega-3 supplementation in children aged 8-10 years from a mainstream school population. Res Dev Disabil 31, 718-730.

35. Osendarp SJ, Baghurst KI, Bryan J, et al. (2007) Effect of a 12-mo micronutrient intervention on learning and memory in well-nourished and marginally nourished school-aged children: 2 parallel, randomized, placebo-controlled studies in Australia and Indonesia. Am J Clin Nutr 86, 1082-1093.

36. Ryan AS \& Nelson EB (2008) Assessing the effect of docosahexaenoic acid on cognitive functions in healthy, preschool children: a randomized, placebo-controlled, double-blind study. Clin Pediatr (Phila) 47, 355-362.

37. Kennedy DO, Jackson PA, Elliott JM, et al. (2009) Cognitive and mood effects of 8 weeks' supplementation with $400 \mathrm{mg}$ or $1000 \mathrm{mg}$ of the omega-3 essential fatty acid docosahexaenoic acid (DHA) in healthy children aged 10-12 years. Nutr Neurosci 12, 48-56. 